\title{
SABERES SOBRE LEITURA EM VIDEOAULAS DE MIDIAS DIGITAIS
}

\author{
Katianny Késia Mendes Negromonte Targino (UFCG) \\ Williany Miranda da Silva (UFCG)
}

Resumo: O desenvolvimento das novas tecnologias da informação e da comunicação (TIC) proporcionou a expansão de cursos livres online, divulgados através de videoaulas, que podem ser acessados por dispositivos móveis, aplicativos, postagens em redes sociais e sites. Nesta perspectiva, a presente pesquisa preocupa-se em refletir sobre os saberes de leitura quando disponíveis nas mídias digitais. Para tanto, tem-se como questão norteadora: Qual a relação entre a concepção de videoaula e o tratamento dado ao ensino de leitura em site destinado a exames de larga escala? Nesse sentido, objetivase identificar e relacionar o objeto videoaula à mobilização de ensino de leitura em vídeo. Para isso, o corpus desta pesquisa é constituído de videoaulas de Língua Portuguesa que tratam desse eixo, veiculadas no site Canal do ensino (http://canaldoensino.com.br/blog/category/ enem). A partir dessa seleção, realizaram-se reflexões teóricas sobre multimodalidade e concepções de ensino leitura, (KLEIMAN, 2008; RIBEIRO, 2016; COSCARELLI, 2016; ZACHARIAS, 2016; MARCUSCHI, 2010) para se compreender a relação entre a abordagem e o uso desse gênero audiovisual para a produção/exposição de conteúdo de leitura. Quanto aos aspectos metodológicos, a investigação é de natureza qualitativa, ancorada no método netnográfico e no estudo de caso. A partir desse tratamento dos dados, foi possível constatar variações do gênero videoaula, o que resulta em diversas concepções de leitura, marcadas pela transição entre os níveis da decodificação e compreensão. Sendo assim, tal democratização do ensino nas mídias digitais exige que professores e alunos tenham olhares críticos para o que está sendo divulgado em rede.

Palavra-chave: Videoaula; Saberes de leitura; Ensino.

Abstract: The development of new information and communication technologies (ICT) has led to the expansion of free online courses, made available through videotapes, which can be accessed by mobile devices, applications, social network posts and websites. In this perspective, 
the present research is concerned with reflecting on the knowledge of reading when available in digital media. To do so, we have as a guiding question: What is the relation between the videotape conception and the treatment given to the teaching of reading on site for largescale exams? In this sense, the objective is to identify and relate the video lessons object to the mobilization of video reading teaching. For this, the corpus of this research is constituted of video-language of Portuguese Language that deal with this axis, transmitted in the site Canal do ensino (http://canaldoensino.com.br/blog/category/enem). Based on this selection, theoretical reflections on multimodality and conceptions of reading teaching were carried out to understand the relationship between approach and use (KLEIMAN, 2008; RIBEIRO, 2016; COSCARELLI, 2016; ZACHARIAS, 2016; MARCUSCHI, 2010) of this audiovisual genre for the production / display of reading content. As for the methodological aspects, the research is of a qualitative nature, anchored in the netnographic method and in the case study. From this treatment of the data, it was possible to verify variations of the genre video lessons, which results in several conceptions of reading, marked by the transition between the levels of decoding and comprehension. Thus, such democratization of digital media education requires that teachers and students have critical looks for what is being disseminated online.

Keyword: Video lessons; Reading skills; Teaching.

\section{CONSIDERAÇÕES INICIAIS}

\subsection{Contextualizando o tema}

O desenvolvimento das novas tecnologias da informação e da comunicação (TIC) tem permitido a democratização do conhecimento escolar em ambientes digitais a partir da expansão de cursos livres online que podem ser acessados por dispositivos móveis, aplicativos, postagens em redes sociais e sites com vistas a divulgar informações. 
As mídias digitais, portanto, tornaram os saberes técnicocientíficos de diversas áreas do conhecimento (Linguagens, matemática, ciências humanas e ciências da natureza) acessíveis aos internautas. Essa propagação de conhecimento estimulou a aprovação e a certificação de cursos técnicos e de graduação a distância, pelo Ministério da Educação e Cultura (MEC), já que a demanda educacional existente no Brasil não é suprida, a curto prazo, pelo modelo presencial de ensino.

Sendo assim, a oferta e a procura por cursos na modalidade a distância (EaD) ganham destaque. Entre 2006 e 2016, o número de ingressantes nessa modalidade saltou de $4,2 \%$ para $18,6 \%$, ocasionando uma queda de $25 \%$ de matrículas nas universidades particulares ${ }^{1}$. Essa procura faz surgir inúmeras discussões, acerca do modo de educar no espaço virtual, em relação à didatização do conhecimento, à interação entre professores e alunos, à flexibilização, produção e execução do planejamento (do trabalho docente). Tais atividades ainda são obscuras nos estudos acadêmicos, embora sejam necessárias para a eficácia do ensino e da aprendizagem mediada pela internet, grande promotor da comunicação em rede.

1 Censo da Educação superior, divulgado pelo INEP, no portal de notícias da educação no G1. In https://g1.globo.com/educacao/noticia/numero-de-novos-alunos-em-cursos-superiorespresenciais-cai-em-2016.ghtml 
Nesse sentido, a web 2.0 promove uma reconfiguração nos modos de ensinar e de aprender, porque suporta aplicativos, imagens e outros recursos que antes o ensino a distância não comportava, o que torna a possibilidade de lidar com objetos de ensino, no caso a linguagem para atividades de leitura e de escrita, de forma mais incrementada e dinâmica.

Visando incrementar as diferentes formas de exposição dos conteúdos, a videoaula tem sido um meio facilitador e complementar na divulgação de assuntos. Adotada por gestores e professores como estratégia educacional a distância. Logo, a escolha desse recurso "implica transformações no processo de criação e de recepção dos textos audiovisuais, uma vez que exploram aspectos como a multimodalidade, a hipertextualidade e a interatividade" (ZACHARIAS, 2016, p.20).

Ao utilizar a linguagem verbal e não verbal para a composição desse gênero, o sistema de processamento da informação e da capacidade da memória de trabalho ativa duas modalidades sensoriais - visual e auditiva, tão úteis para as elaborações cognitivas do objeto a ser ensinado, a leitura (FILATRO, 2008).

Sendo assim, a exposição de conteúdos, nos diferentes cursos online, disponíveis na web, tem um "grande potencial 
de estímulo sensorial, pois conta com o auxílio da associação de elementos visuais, sonoros e interativos com o objetivo de transmitir, de forma eficiente, uma mensagem, estimulando o processo cognitivo dos usuários" (OLIVEIRA; STANDLER, 2014, p.2). A disposição dos diferentes recursos audiovisuais provoca uma diversidade de formato, funcionamento e uso desse gênero a depender do conteúdo que é exposto.

No plano da leitura, o ambiente digital permitiu a ampliação do acesso e da facilidade de distribuição de livros em arquivos digitais, bem como, vídeos que ensinam técnicas de leitura dinâmica e até mesmo estratégias de ler; contudo, a propagação e difusão de textos na web não são necessariamente fatores determinantes para o desenvolvimento de habilidades de leitura, tais como: ler, compreender, interagir, criticar, relacionar e comparar (RIBEIRO, 2016).

Essas mudanças, na forma de processar a leitura, reforçam a necessidade de os professores estarem atentos à organização e ao funcionamento do ambiente digital, como alternativa complementar e motivadora para reflexões sobre a linguagem de um modo geral, em seus diversos eixos de ensino, seja na modalidade presencial ou a distância (RIBEIRO, 2016). 
Nesta perspectiva, nossa investigação justifica-se, pois, pela recorrência de instrumentos de leitura disponíveis para auxiliar usuários, candidatos a uma vaga no ensino superior, especialistas da área, ou até mesmo, qualquer usuário curioso que tenha disponível a informação desejada. Assim, a presente pesquisa tem a seguinte questão norteadora: Qual a relação entre a concepção de videoaula e o tratamento dado ao ensino de leitura em site destinado a exames de larga escala? Diante desse questionamento, espera-se compreender uma possível relação entre a abordagem de ensino de leitura e o uso desse gênero audiovisual para a produção/exposição de conteúdo específico da disciplina de língua. Nesse sentido, faz-se necessário identificar e relacionar o objeto videoaula à mobilização de ensino de leitura em vídeo. Para isso, o corpus desta pesquisa é constituído de videoaulas de Língua Portuguesa que tratam do eixo de leitura, veiculadas no site Canal do ensino (http:// canaldoensino.com.br/blog/category/enem)².

De forma geral, a presente investigação está organizada em cinco partes. Sendo a primeira, esta introdução, que buscou

2 Este canal é um dos ambientes estudados na dissertação, “Didatização de saberes sobre leitura e escrita em ambientes digitais para exames de larga escala", a ser defendida em 2019, pelo PPGLE-UFCG. Além disso, a autora se ocupa de outras videoaulas expostas em três canais: http://www.mandebemnoenem.com/mandebem-na-midia.aspx; https://mesalva.com/cursos; http://ensinomediodigital.fgv.br/staticpages/acessoaos-cursos-deslogado.aspx, abordando os eixos de leitura e escrita. 
contextualizar a temática sobre a democratização do ensino via internet, bem como, a função didática das videoaulas para mediar a exposição de conteúdos. A segunda discorre sobre os procedimentos metodológicos da coleta e geração de dados. As duas próximas seções foram organizadas, tendo como ponto de partida os aspectos teóricos sobre esse aparato tecnológico a favor leitura no ambiente digital, analisados a partir de um recorte sistematizado dos dados e analisados à luz dos seguintes autores: KLEIMAN, 2008; RIBEIRO, 2016; COSCARELLI, 2016; ZACHARIAS, 2016; MARCUSCHI, 2010, entre outros. Por fim, a quinta parte apresenta as considerações finais com as reflexões sobre os resultados obtidos e as implicações do ensino de leitura a distância e longe dos bancos escolares tradicionais.

\subsection{Explicitando o percurso: Da abordagem metodológica às categorias de análise}

A metodologia desenvolvida é de abordagem qualitativa, visto que descrevemos e interpretamos dados que não podem ser facilmente descritos numericamente (FRAGOSO, 2013). Para tanto, em vista de um melhor tratamento do nosso corpus, os métodos, que melhor se adequam ao perfil dessa pesquisa, são dois - estudo de caso e a netnografia.

O primeiro tem como pretensão principal estudar detalhadamente um dado contexto, realidade, grupo e 
indivíduos; ou seja, assume uma visão particular, pois procura compreender o objeto de estudo diante de uma perspectiva pragmática e global (FONSECA, 2002). Pela necessidade de debruçarmos o olhar sobre um conjunto de videoaulas de leitura presentes no site "Canal do Ensino" (http:// canaldoensino.com.br/blog/), foi fundamental a seleção desse método, já que é capaz de focalizar a observação em uma unidade de análise.

Além disso, esta pesquisa também se situa nos estudos netnográficos3, já que preza pelo trabalho de observação do corpus de análise no ambiente digital, bem como, pela inserção do pesquisador na comunidade de pesquisa (AMARAL et al., 2008). Esse método troca o campo face a face pela investigação no meio virtual, sendo necessário para a sistematização da coleta de dados, os prints de tela que permitem a visualização do nosso objeto de estudo, através de imagens, e fragmentos transcritos que elucidam a abordagem dos conteúdos explicitados em vídeos.

Apartirdessesinstrumentos, selecionadosporamostragem, foi possível a análise e a caracterização das videoaulas e do site que as suportam. O ambiente Canal do ensino, por sua

\footnotetext{
3 A netnografia é um termo oriundo da técnica de pesquisa da etnografia, desenvolvida no campo da antropologia. Esse método tem crescido em virtude do desenvolvimento das sociedades digitais, cujas pesquisas trocam-se o campo face a face pelo virtual (MONTARDO; PASSERINO, 2006).
} 
vez, é caracterizado como um portal dedicado à educação, que está na rede desde o ano de 2012, para compartilhar cursos gratuitos, livros de domínio público, vídeos, dicas de concursos e dicas para professores e alunos sobre tecnologia educacional. Os administradores não são identificados e as videoaulas estão disponíveis gratuitamente, isto é, não são arquivos restritos, possibilitando o download ${ }^{4}$; e funcionam como um veículo de divulgação e de comercialização de cursos a distância. As postagens estão organizadas por disciplinas (história, matemática, português, etc), através de abas que é um recurso próprio da web 2.0 em que aparece logo abaixo da foto de capa, sendo possível abrir várias informações, a partir de links, em uma mesma página ou em outra diferente. A fim de ilustrar essa disposição, vejamos a página inicial do site 1 :

4 Esse termo faz referência à possibilidade de baixar vídeos, imagens, entre outros recursos disponíveis no ambiente web. 


\section{Ensino

F

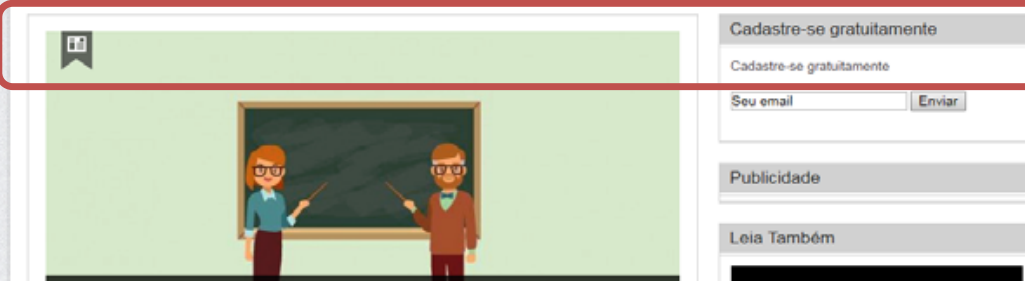

Figura 1: Página inicial do site (Canal do Ensino). Fonte: In https://canaldoensino.com.br. Acesso 13.Jul.2018.

O recorte exposto na Figura 1 apresenta a página inicial do site que é organizada em oito abas, intituladas, bolsas de estudo, cursos grátis, concursos e empregos, dicas, Enem, livros grátis, mais popular e videoaula, conforme a sinalização retangular em torno delas. A busca pelo nosso objeto de pesquisa ocorreu através da última aba (videoaula) e de pesquisas personalizadas pela ferramenta do Google, como está indicada a partir da seta, centralizada na parte superior da esquerda para direita.

Nessa procura, constatamos que, no site 1 , na área de Língua Portuguesa há 13 vídeos de leitura, 7 de escrita e 115 de gramática. Para este artigo, o interesse está para os que tratam o eixo de ensino de leitura, em virtude da 
recorrência e da diversidade de formatos e funcionamento ao explorarem os recursos da multimodalidade ante a abordagem do conteúdo.

Durante a exposição, verifica-se que as videoaulas se configuram como um gênero audiovisual, em virtude de apresentarem uma organização recorrente, quanto à estrutura e ao funcionamento. No que corresponde ao formato, é possível constatar, que a duração, isto é, o tempo médio de exibição, é entre $05 \mathrm{~min}$ e $1 \mathrm{~h}$; e os recursos utilizados são o auditivo, representado pela voz do sujeito que expõe o conteúdo e o visual que dispõe de quadro, papel, pincel, atuação de um sujeito.

Em relação ao funcionamento, que corresponde à mobilização de estratégias didáticas para a apresentação do conteúdo, verifica-se a abertura da aula: identificação do sujeito e conteúdo; exposição de conceitos; demonstração de exemplos; sugestão de atividades; fechamento.

Ao estabelecer o entrecruzamento entre forma e funcionamento, constata-se uma variedade de formatos de vídeos, popularizados como videoaulas. Dos treze produtos, um pode ser identificado como aula gravada, visto que a gravação ocorre no momento de execução da aula em âmbito presencial. Nela, observa-se interação com o público, já que 
há a presença de plateia. Nove são sinalizados como vídeos instrucionais, cujo foco está para o treinamento da ação de ler com rapidez, sem necessariamente ter a mobilização de estratégias de leitura. Três podem ser caracterizados como videoaulas, uma vez que funcionam como materiais de apoio às atividades didáticas, têm um público-alvo pré-definido, um contexto de produção e objetivos didáticos para serem atingidos, mediante a grade de assuntos proposta pelos cursos a distância (MARCUSCHI, 2010).

Cada um desses formatos revela diferentes estruturas e funcionamentos, diante disso, nota-se que há uma flexibilização na abordagem do eixo de leitura, o que diz sobre o tratamento dado aos conteúdos. Com o objetivo de organizar os dados, a análise é de base teórico-analítica, intitulada "Ensinando a ler a partir de vídeos". Para essa abordagem, as discussões sobre a relação entre os tipos de vídeos e a concepção de ensino serão sistematizadas nos tópicos que seguem.

\section{ENSINANDO A LER A PARTIR DE VÍDEOS}

A inserção das tecnologias digitais na vida cotidiana tem provocado mudanças nas formas de interação e de comunicação das pessoas, bem como, a reconfiguração das práticas de leitura. A emergência de textos multimodais, que 
associam sons, ícones, imagens estáticas e em movimento, alterou o processamento da informação e da construção de significados dos leitores (ZACHARIAS, 2016).

Nesse contexto, o processo de ler se torna ainda mais complexo, visto que as mídias nas quais esses textos são disponibilizados têm a tela como principal suporte, o que requer conhecimentos que não se restringem a escrita alfabética, exigindo, portanto, outras habilidades, tais como, interpretar, compreender e significar elementos verbais e não verbais presentes nos diferentes gêneros do ambiente digital.

Essas atividades provocam a interação entre o pensamento e a linguagem. Logo, a internet tem "representado formas de participação e hábitos de ler ubíquos, plurais, menos hierárquicos e menos lineares" (ZACHARIAS, p.16). Para a realização da compreensão de textos, segundo Goodman (1976 Apud KLEIMAN, 2008), três tipos de informações são utilizados: 1) informação grafo-fônica, que inclui os aspectos gráficos e fonológicos e a interrelação entre ambas; 2) informação sintática, que consiste na organização do vocabulário em unidades sequenciais supridas pelo leitor; 3) informação semântica, que corresponde tanto ao vocabulário quanto aos conceitos e experiências dos leitores. 
Aliada a esses três tipos de informações, surge, com as TIC, a informação audiovisual que inclui a habilidade de interpretar o que se vê e o que se ouve através de recursos multimidiáticos e multissemióticos do ambiente digital. Nessa proposta, a leitura é construtiva e é um processo de integração de várias operações. Então, diante de um texto, segundo Zacharias (2016), é preciso dispor de conhecimentos prévios, linguísticos e de mundo para atribuir sentido às palavras e às frases em determinados contextos.

Diante desse contexto, segundo Kleiman (2008), ler é um processo dinâmico e interativo, no sentido de que os diversos conhecimentos interagem e acionam habilidades metacognitivas, sendo essas: fazer predições, isto é, levantamento de hipóteses, ativação de esquemas ou de redes mentais; produzir inferências, tanto de informações implícitas quanto explícitas.

Sendo assim, para Coscarelli e Novais (2010, p.36),

ler envolve desde a percepção de elementos gráficos do texto até a produção de inferências e a depreensão da ideia global, a integração conceptual, passando pelo processo lexical, morfossintático, semântico, considerando fatores pragmáticos e discursivos, imprescindíveis à construção de sentido. 
Isso significa dizer que para ser um leitor proficiente é necessário mobilizar três níveis de leitura, que segundo Colaço (1998 Apud ARAÚJO 2014), são: explícito, implícito e metaplícito. O primeiro consiste no saber da decodificação, isto é, o reconhecimento da materialidade linguística; o segundo diz respeito à compreensão, em que é preciso levantar inferências e intenções do autor através de elementos linguísticos, logo, há o jogo entre o dito e o não dito. Por fim, o terceiro nível corresponde à interpretação da ideia global do texto e a construção de posicionamentos.

Tais níveis evocam que ler é uma tarefa complexa, visto que "além dos aspectos puramente cognitivos como decodificação linguística, o empenho do leitor no (re)arranjo de informações textuais se mostra decisivo" para a aquisição da fluência, seja oral ou silenciosa; para a identificação de inferências, para a interpretação e o desenvolvimento do senso crítico diante dos textos com as múltiplas semioses. Essas habilidades revelam o grande desafio dos professores ao tomar como objeto de ensino esse eixo. (ARAÚJO; SILVEIRA, 2017, p.38).

Na prática escolar, o ensino da leitura fundamenta-se em diferentes abordagens pedagógicas, de aprendizagem e de linguagem. Ao migrar para o ambiente digital, através de aula 
gravada, de vídeo instrucional e de videoaulas, também se constatam concepções de leitura na exposição de conteúdos. A seguir, o Quadro 1 apresenta uma sistematização dessa variação no tratamento dado ao eixo de leitura:

\begin{tabular}{|c|c|c|c|}
\hline $\begin{array}{c}\text { PRODUTOS } \\
\text { DIGITAIS } \\
\text { (VIDEOS) }\end{array}$ & RECORRÊNCIA & $\begin{array}{c}\text { TRATAMENTO DO } \\
\text { CONTEÚDO DE LEITURA }\end{array}$ & $\begin{array}{c}\text { CONCEPÇÃO DE } \\
\text { ENSINO }\end{array}$ \\
\hline Aula gravada & 1 & $\begin{array}{l}\text { Estratégias de exemplificação } \\
\text { indireta por abstração da } \\
\text { informação. Ex: atentar para } \\
\text { o movimento do globo } \\
\text { ocular; concentrar-se e } \\
\text { imaginar o que está lendo; } \\
\text { fazer exercícios de fixação }\end{array}$ & $\begin{array}{l}\text { Decodificação/ } \\
\text { memorização }\end{array}$ \\
\hline $\begin{array}{c}\text { Vídeo } \\
\text { instrucional }\end{array}$ & 9 & $\begin{array}{l}\text { Estratégias de exemplificação } \\
\text { indireta por recorrência } \\
\text { consciente da informação. } \\
\text { Ex: grifar textos, fichar, } \\
\text { indicações de livros }\end{array}$ & $\begin{array}{l}\text { Decodificação/ } \\
\text { memorização }\end{array}$ \\
\hline Videoaula & 3 & $\begin{array}{l}\text { Estratégias de conceituação: } \\
\text { reconhecer pistas textuais; } \\
\text { identificar informações } \\
\text { explícitas e implícitas, a } \\
\text { partir de inferências. }\end{array}$ & $\begin{array}{l}\text { Hibridismo entre a } \\
\text { decodificação e } \\
\text { compreensão }\end{array}$ \\
\hline
\end{tabular}

Quadro 1: Caracterização de produtos digitais e a concepção de ensino de leitura. Fonte: Autora.

O Quadro 1 "Caraterização dos tipos de vídeos de leitura e a concepção de ensino" apresenta quatro colunas para identificar a existência do material nos suportes selecionados 
(site 1 - Canal do ensino). A primeira coluna faz referência ao tipo de vídeo e a segunda revela a quantidade de cada produto digital, neste caso, trata-se da recorrência de (1) aula gravada, (9) vídeos instrucionais e (3) videoaulas para a abordagem de assuntos. Essa variação de formatos para o gênero audiovisual- videoaula - revela diferentes utilizações de estratégias didáticas e de recursos multimídias para a exposição do conteúdo, como sinaliza a terceira coluna ao evidenciar o tratamento dado ao conteúdo de leitura. Essa demonstração didática, como por exemplo, "Concentrar-se e imaginar o que está lendo, grifar textos, fichar, reconhecer pistas textuais", aponta para concepções de ensino de leitura, conforme indicada na quarta coluna.

Sob esta ótica, a aula gravada e os vídeos instrucionais tratam o ensino de leitura sob o nível da decodificação, enquanto as videoaulas de leitura estão na fronteira entre os níveis de decodificação e compreensão. A título de ilustração, cada tipo de vídeo será analisado e descrito, nos próximos subtópicos.

\subsection{Leitura em aulas gravadas e vídeo instrucional}

O ensino da leitura no ambiente digital é exposto em diferentes tipos de vídeos, aula gravada e vídeo instrucional. Essa diversidade de formatos é perceptível em virtude 
da versatilidade, rapidez, dinamicidade das atividades comunicativas do ambiente digital, o que faz com que os gêneros textuais se multipliquem exponencialmente, igualmente às práticas sociais e às formas de interação (MARCUSCHI, 2010). Tal demanda exige do leitor e do professor uma constante reconstrução e atualização de atividades de leitura, pois cada texto exige diferentes formas de ler e interagir. Vejamos um dos formatos que concretiza a diversidade de estratégias para exibição do conteúdo "Técnicas para leitura concentrada", na reprodução da imagem da Figura 1, referente a uma aula:

\section{Técnicas para leitura concentrada}

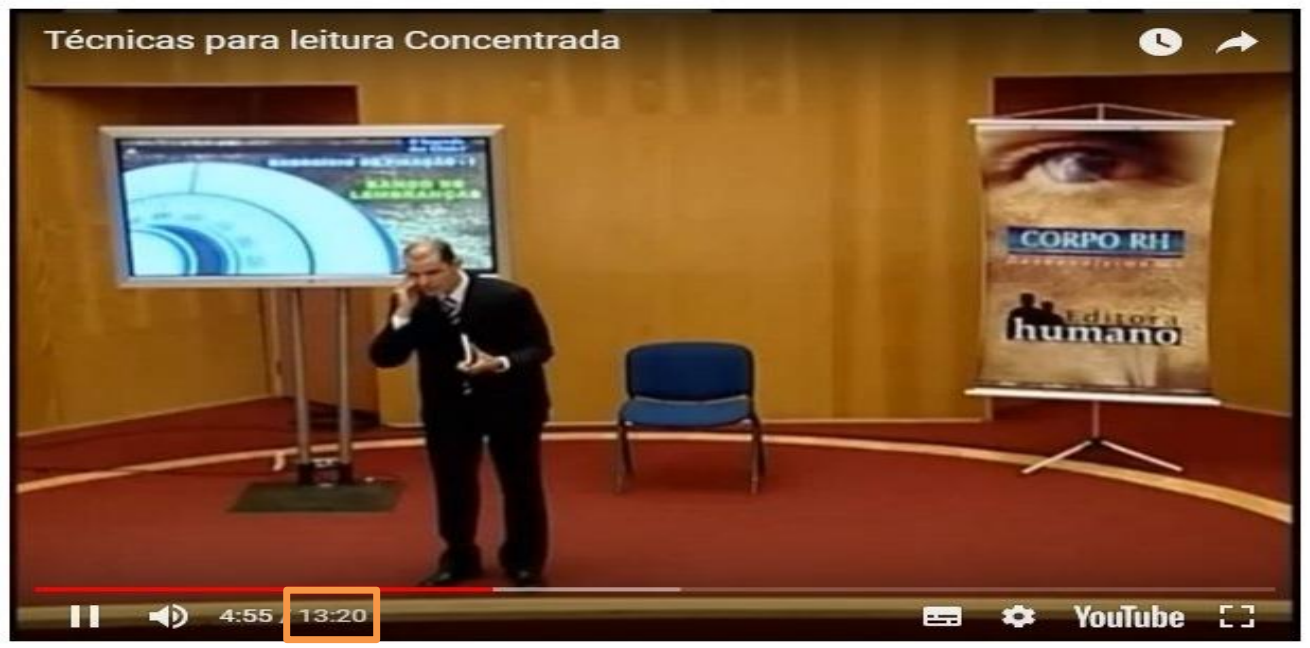

Figura 1: Aula gravada. In https://canaldoensino.com.br/blog/15-videos-sobre-tecnicasde-leitura. Acesso em 11.Jun.2018. 
O recorte exposto reproduz uma imagem de aula gravada, recolhida do site em estudo, intitulada "Técnicas para leitura concentrada". Observa-se, que a média de tempo de exibição é de treze minutos e vinte segundos (13:20 min), em destaque no canto inferior esquerdo e que o ambiente de circulação é, além do site em foco, a rede social, Youtube, em destaque no canto inferior direito, possibilitando o acesso ao material por ambos os ambientes.

A imagem reproduz um cenário similar a um auditório, em que um sujeito ocupa o centro do palco, tendo como complemento uma cadeira vazia e dois suportes de projeção (TV e expositor) para apresentar aos ouvintes slides sobre estratégias de memorização daquilo que se lê. Por se tratar de uma imagem em movimento (vídeo), durante a exposição do conteúdo, há a ocorrência de diferentes enfoques, ora centrada no sujeito, ora, no público, ora na imagem projetada na TV. Essa diversidade de ângulos de visão revela a potencialidade do recurso- vídeo - ante a exposição do conteúdo.

No momento de captura, foram contabilizadas 14.292 visualizações, o que revela o interesse, curiosidade ou necessidade de adquirir conhecimentos de conteúdos escolares, no eixo de ensino da Língua Portuguesa, pelos 
usuários que acessam a referida rede social. O acesso a essa aula é possível tanto pelo site quanto pelo canal Youtube, sem ocorrência de cadastro ou qualquer outra restrição para a sua visualização.

O ambiente de produção que o apresentador se encontra (palco) e a interação com os ouvintes no momento da apresentação demonstram que se trata de uma aula gravada, visto que a gravação ocorre no instante de sua execução.

Nesse sentido, observa-se um roteiro planejado para atender ao evento comunicativo aula presencial do curso "Técnicas de leitura concentrada", sem ocorrer as adequações para o ambiente digital, visto que para produção do vídeo é necessário que o sujeito tenha o auxílio de tutores em estúdio, a fim de que se possa aliar as multimídias ao processo de ensino-aprendizagem, no intuito de ilustrar, reforçar e complementar um conteúdo educacional proposto por uma instituição que oferece cursos a distância (BARRÉRE, 2014).

Diante desse contexto, a linguagem audiovisual é integrada às diferentes formas de ensinar, através de estratégias de didatização, semelhantes à situação de aulas presenciais, sendo estas: abertura da aula: identificação do sujeito e do conteúdo (1); exposição de conceitos (2); demonstração de exemplos (3); sugestão de atividades (4) e fechamento (5). 
A fim de ilustrar tais recorrências, vejamos a transcrição dos 10 primeiros segundos e entre um minuto e 16 segundos e 27 segundos.

Trecho $1^{5}$ :

Vejamos agora uma ficha de lembrança. Quando eu penso no filme Titanic, eu me lembro de. Você acha que conseguiria se lembrar de muita coisa ou de pouca coisa? Pausa (resposta do público ouvinte). Já está lembrando. Só de tocar no assunto já está lembrando [...] durante a leitura imagine personagens, local, objetos. Isso para um texto mais fácil, um texto técnico gente, eu não tenho que ler, eu tenho que estudar.

Fonte: https://www.youtube.com/watch?v=6ZA6x88sXyo. Acesso em 12.Ago.2018.

Esse fragmento sinaliza o início da aula, que parte da estratégia de exibição de exemplos, ao citar o filme "Titanic" para situar o poder da memória visual, de longa duração, associado ao interesse daquilo que se lê. Neste caso, para tratar o ensino da leitura, o sujeito, não identificado no vídeo, contudo, o intitularemos como professor virtual, visto que ocupa o papel de um docente em um ambiente digital, parte de saberes procedimentais, que na perspectiva de Zabala (2009) vinculam-se a um conjunto de ações ordenadas e orientadas para a realização de um objetivo. Ao longo de toda exibição, portanto, são expostos procedimentos e técnicas de memorização, tais como: “imagine personagens,

5 A transcrição realizada tomou como ponto de partidas as regras do NURC. 
local, objetos" que auxiliam a capacidade de retenção de informações daquilo que se lê.

Nesse sentido, a estratégia didática utilizada para garantir o funcionamento da aula foi a demonstração de exemplo. As exemplificações, embora elucidativas, pretenderam instrumentalizar o conteúdo, uma vez que foram trabalhadas do ponto de vista da abstração (conforme destacado no Quadro 1), sem que ocorresse, necessariamente, a partir de um texto.

Essa abordagem de leitura está para a prática associativa, no âmbito da decodificação. Embora o reconhecimento da materialidade linguística que leva o leitor iniciante a identificar frases, palavras, o gênero textual e a situação comunicativa exija bastante empenho, quando se trata de um leitor mais proficiente, já se torna um processo automático (ARAÚJO, 2014).

Nesse sentido, a restrição do ensino de leitura baseada, exclusivamente, na informação linguística revela ser insuficiente, tendo em vista que a compreensão e interpretação de textos são uma atividade social, contextualizada, que envolve aspectos históricos, dialógicos e culturais (KLEIMAN, 2008).

Em síntese, ao se observar a forma e o funcionamento deste vídeo é possível constatar que se trata de uma aula 
gravada. Tanto em virtude do ambiente de ocorrência da aula e da plateia existente no vídeo e as mídias utilizadas, quanto das estratégias didáticas. Dentre as cinco estratégias apontadas, nota-se a eleição de uma delas- a demonstração de exemplos, como fundamental. Essa ausência revela que a função didático-pedagógica fica comprometida ao migrar do contexto de ensino presencial para o ambiente digital, à revelia das adaptações necessárias ao novo ambiente de circulação, que exige alterações para as especificidades composicionais que corresponde à estrutura, estilísticas que dizem respeito à linguagem e temáticas que consistem no assunto a ser tratado.

Vejamos outra ocorrência com o mesmo tema- ensino de leitura em vídeos instrucionais. 
5 G fotos coração passic [ filmes N Netflix $\mathbf{X}$ G $1600 \times 1200$-pasto If OSolicitações

Para começar a melhorar a forma como lê, essas dicas podem ser bem úteis.

\section{5 dicas para ser um leitor melhor}

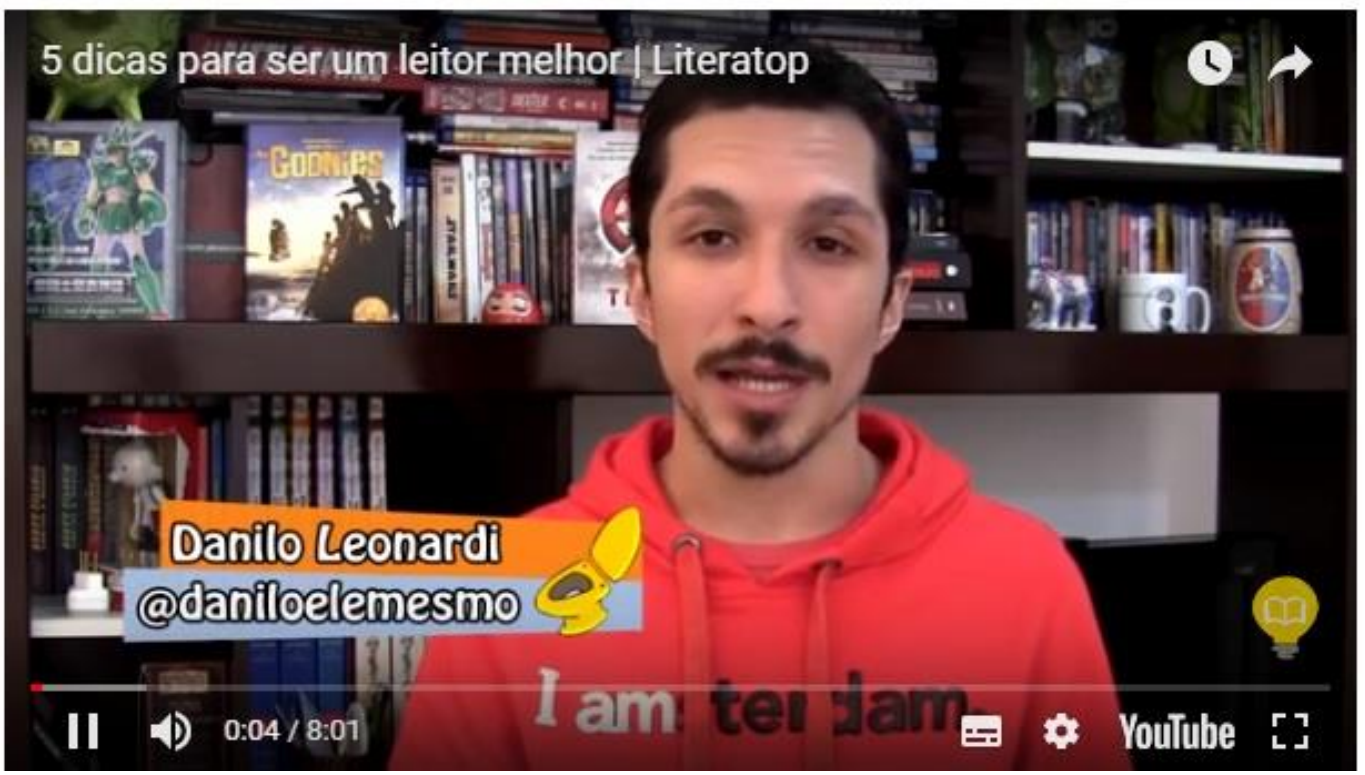

Figura 2: Vídeo instrucional. In https://canaldoensino.com.br/blog/15-videos-sobretecnicas-de-leitura. Acesso em 14.Jun.2018.

A imagem, destacada na Figura 2, está presente no site em estudo e armazenada no YouTube (sinalização retangular, canto inferior direito). Ela é parte integrante do canal Cabine Literária, representado pela logomarca de uma lâmpada que integra um livro (reproduzido acima do nome Youtube). Esse canal tem 159 mil inscritos e o vídeo teve 156.808 visualizações. 
Tais dados constatam a popularização desse ambiente, bem como, o interesse dos usuários pelo conteúdo de leitura.

O tempo médio de duração é de oito minutos e um segundo (especificado no canto inferior esquerdo, evidenciado no rodapé da imagem a partir da forma geométrica retangular. Quanto aos recursos audiovisuais constata-se a presença de um sujeito que expõe cinco dicas de leitura, identificado através de uma legenda que apresenta o nome "Danilo Leonardi" e o seu endereço da rede social Instagram @ daniloelemesmo.

Ao longo da exibição, nota-se que duas estratégias didáticas foram mobilizadas para a abordagem de dicas de leitura: demonstração de exemplos e fechamento. A transcrição a seguir, demarcada nos intervalos de tempo (48 segundos; 1 minuto e 42 segundos; 3 minutos; 4 minutos e 16 segundos; 5 minutos e 18 segundos), evidencia essa recorrência, vejamos:

Trecho 2:

A primeira dica que eu tenho para dar a vocês é ligue o seu cérebro [...] A segunda dica que eu tenho para dar para vocês é nada é por acaso [...] A dica número três é anotar é preciso [...] A dica número quatro é um pouco polêmica, porque marcar é inevitável [...] A dica número cinco é leia os clássicos [...].

Fonte: https://canaldoensino.com.br/blog/15-videos-sobre-tecnicas-de-leitura. Acesso em 12.Ago.2018. 
O Trecho 2 apresenta as instruções dadas pelo sujeito ao ler livros. Cada uma delas é demonstrada a partir de exemplos de obras literárias. Nota-se que o conteúdo leitura é apresentado no âmbito da informalidade e do senso comum, sem ter um respaldo teórico-científico. Essa constatação advém da enumeração de cinco dicas: "(1) ligue seu cérebro", que consiste em atentar para os aspectos positivos e negativos do livro; "(2) nada é por acaso", que corresponde aos propósitos comunicativos da linguagem da obra; "(3) anotar é preciso”, diz respeito à memorização daquilo que se lê; "(4) marcar é inevitável”, refere-se aos grifos de trechos principais; e, por fim, "(5) leia os clássicos", que reverbera a recomendação para leitura de obras literárias de caráter atemporal.

A exposição de dicas demonstra uma perspectiva de leitura linear, centrada na decodificação de signos e no desbravamento dos sentidos pretendidos pelo autor. Contudo, segundo Zacharias (2016), ler é uma atividade de ação fluida, cuja valorização do ensino hierárquico em que se aprendia: palavras, frases e depois textos deu espaço para as intenções do leitor, seus recursos cognitivos prévios e suas hipóteses sobre o texto.

Nesse contexto, o tratamento dado ao eixo de leitura revela que o vídeo é de natureza instrucional, isto é, normativo, que segundo Cardoso (2013, p.81), 
por si só, pode não ser suficiente, deve fazer parte de todo um contexto de interação entre alunos e tutores, alunos e alunos, e isso, acreditamos, se aplica a qualquer material instrucional, quer seja ele impresso ou digital. A interação seria a chave de um aprendizado significativo.

A partir dessa assertiva, o vídeo tem uma eficácia pedagógica no processo educacional, contudo se mostra complementar as situações de ensino-aprendizagem, visto que não há o ensino de habilidades de leitura, tais como: inferir, comparar e relacionar, mas um treinamento mecânico para a ação de ler, sem a demonstração das dicas a partir de textos (BARBOSA; SILVA, 2017). Outra estratégia didática que aparece é a de fechamento, vejamos a seguir o Trecho 3 que a comprove:

Trecho 3:

Existem muitas maneiras de se tornar um leitor melhor e como eu disse é um trabalho contínuo e se você tiver outras dicas para compartilhar com a galera escreve aí embaixo, quem sabe eu não faço uma segunda edição? De toda forma, espero que você tenha gostado e que essas dicas realmente te ajudem na sua formação como leitor. E se gostou, clica em gostei, favorite esse vídeo e se inscreva no canal e não deixe de visitar o nosso site (aparece o link- www.cabineliteraria. com.br). Até a próxima.

O Trecho 3 mostra a estratégia de fechamento. 0 apresentador utiliza a técnica de síntese para concluir a sua 
fala, ao dizer "Existem muitas maneiras de se tornar um leitor melhor e como eu disse é um trabalho contínuo." Verificase também uma interação com o usuário, ao solicitar que escreva outras dicas de leitura, que podem ser divulgadas no site e no canal do Youtube que o apresentador gerencia, para que no próximo vídeo sejam socializadas mais instruções. Tal atitude evidencia que o saber pode ser compartilhado e construído, visto que não se trata de um especialista, mas de um leitor experiente.

Em suma, o vídeo instrucional expõe o conteúdo, a partir de experiências de leitura vivenciadas pelo apresentador, sem necessariamente ser de natureza pedagógica e voltado para atender a cursos on-line.

No próximo tópico, discorreremos sobre a concepção de ensino de leitura apresentada no gênero videoaula, bem como, suas características estilísticas e composicionais.

\subsection{Leitura em Videoaulas}

No contexto educativo a distância, o ensino de leitura pode ser viabilizado através do gênero videoaula, que alia recursos verbais e não verbais para adaptar o evento de letramentoaula do contexto presencial ao ambiente digital- através do suporte vídeo. Apesar de ser relativamente variado, apresenta traços diferentes e similares com o ambiente 
presencial. Segundo Dominguez (2014), a semelhança consiste na sua funcionalidade de construir o conhecimento enquanto que em relação às diferenças destaca-se sua natureza assíncrona, isto é, a interação não ocorre em tempo real. Logo, os usuários têm a vantagem de poderem escolher o momento mais adequado para acessá-la.

Dessa forma, os gêneros emergentes da tecnologia digital são complexos, visto que se transmutam e se mesclam a partir de gêneros já existentes, constituindo-se, portanto, em modalidades que já existem, contando com a ampliação e modernização de práticas digitais. Apesar de o gênero videoaula emergir a partir de um evento comunicativo que já ocorre - a aula -, o mesmo faz parte da esfera digital "pelas especificidades que o modo de ser digital implica para a configuração dos enunciados, no que diz respeito à composição, à temática e ao estilo, emerge" (PEREIRA, 2014, p.54).

A organização textual de um gênero, na perspectiva do Interacionismo sócio discursivo, segundo Miranda (2015, p.222), "é concebida como configurações textuais relativamente estabilizadas ou cristalizadas que se associam a diversas atividades de linguagem". Sob esta ótica, composicionalmente, as videoaulas utilizam o recurso tecnológico (vídeo), o qual mobiliza diversas semioses, 
a linguagem verbal (no seu modo oral ou escrito) que interage com outros sistemas de significação: a linguagem corporal, visual, auditiva e espacial.

Neste caso, os diversos recursos multimodais estão a serviço da divulgação de conteúdos técnico-científicos de forma ampla e coletiva para um usuário que deseja ingressar no ensino superior ou aprimorar conhecimentos. Logo, tratase de um produto que modela a ação didática, envolvendo não apenas aspectos imagéticos, relacionados ao conteúdo tratado como também a fala planejada.

Para tal façanha, pressupõe-se um agente, não exclusivamente um professor, como o que está na aula presencial, mas uma ação "teatral" atenta às novas demandas de ensino com vistas a perpetuar o objetivo do professor de língua materna: tomar o texto, em sua diversidade, como objeto para o ensino de leitura em seu planejamento diário na atuação docente (VIEIRA; SILVESTRA, 2015).

Nesse contexto educativo, as videoaulas, assim como, a aula gravada e o vídeo instrucional dispõem de recursos multimodais (ângulos, efeitos sonoros, jogo de cores, formato de letras), que as constituem, são chamados de modos, do qual deriva o termo multimodalidade que faz parte de uma área de estudo mais ampla: a semiótica social, 
para potencializar a exposição do conteúdo (VELOSO, 2014). Essa combinação de elementos assume funções significativas na construção de significados no texto e quando tem um viés ou uma finalidade pedagógica facilita o processo de ensino-aprendizagem, pois segundo a teoria cognitiva da aprendizagem multimodal, desenvolvida por Mayer (2001),

os estudantes aprendem melhor a partir de uma explanação apresentada em palavras e em imagens do que apenas em palavras e defende que a utilização apenas do modo verbal, ou seja, da construção da informação apenas pelo uso da palavra, desconsidera o potencial do sistema humano de processamento do modo visual. (DIONISIO, 2013, p.34)

Corroborando com o posicionamento de Mayer, a integração de mais de um modo semiótico - visual e auditivocontribui para grande potencialidade didática e pedagógica para difundir e disseminar o conhecimento, já que a capacidade de processamento de informação é ampliada, em virtude de vários sentidos que evoca: imagem e som, além de palavras. Sob esta ótica, tratam-se de materiais didáticos, visto que podem ser utilizados pelos professores para servir ao ensino com várias funções, dentre elas, atuar como fonte de referência para o trabalho docente (estudo e ensino), seja complementando ou ampliando os conteúdos, e apresentar 
um conjunto de atividades para o ensino aprendizagem dos mesmos, distribuindo-se de acordo com a progressão do tempo escolar.

Além disso, podem instrumentalizar o professor e o aluno para um aprendizado mais consistente. Portanto, tornar a sua produção mais dinâmica e exequível é condição primeira para que o aluno se interesse pelo conteúdo, embora, esse gênero, assim como qualquer outro, seja fruto de relações entre um meio, um uso e uma linguagem, capaz de provocar variações composicionais.

Para tanto, vejamos a seguir um exemplo desse gênero do site em estudo: 


\section{Mais eficiente que leitura dinâmica: leitura ativa}

\section{Máis eficiente que "leitura dinâmica": leitura ativa!}
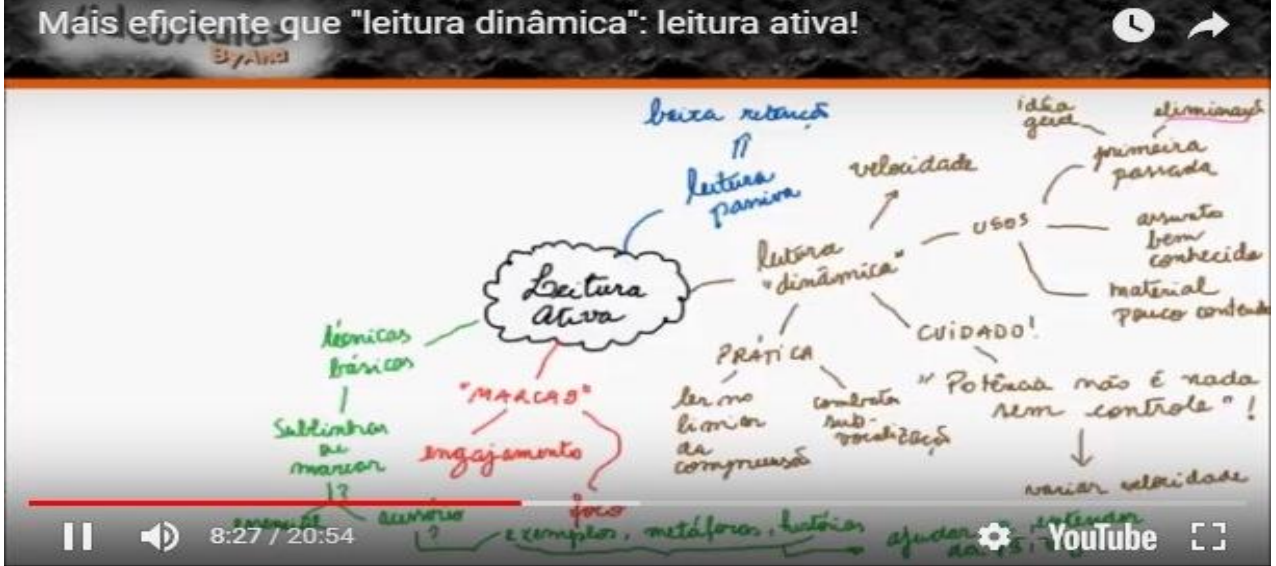

Figura 3: Videoaula: Mais eficiente que leitura dinâmica: leitura ativa. Site 1 In https:// canaldoensino.com.br/blog/15-videos-sobre-tecnicas-de-leitura. Acesso em 18.Jun.2018.

Dentre as 3 videoaulas presente no site Canal do Ensino, a Figura 3 reproduz uma imagem que remete a uma delas, intitulada "Mais eficiente que leitura dinâmica: leitura ativa", também aportada na rede social, sinalizada no canto inferior direito da imagem "Youtube". Dentre os 13 vídeos de leitura deste site, esta é a que teve maiores visualizações, cerca de 282.206 usuários acessaram-na no ambiente digital. O tempo de duração é em média 21 minutos (marcado pelo círculo na parte inferior do lado esquerdo). Em relação ao visual, verifica-se que o apresentador é identificado pelo 
recurso sonoro, o plano de fundo é alterado à medida que é preenchido com tópicos conceituais da fala do sujeito que expõe o conteúdo. A diversidade de cores na tela (vermelho, verde, azul, amarelo) presta-se a explicar o que é a leitura ativa, além de envolver o usuário para o que é evidenciado na discussão.

Nesse contexto, percebe-se a utilização da multimodalidade para a compreensão do conteúdo "leitura ativa", pois há a evidência de elementos verbais e nãoverbais para compor a cena (VELOSO, 2014). Quanto aos aspectos do funcionamento, observa-se que se trata de uma videoaula e que nela há a presença das seguintes estratégias didáticas: abertura da aula: identificação do sujeito e do conteúdo (1); exposição de conceitos (2); demonstração de exemplos (3); fechamento (4). Para este tópico, é do nosso interesse destacar as estratégias (1, 2 e 3), visto que traz indícios do ensino de leitura. Vejamos trechos da exibição que exemplifique tais ocorrências: 
Trecho 4:

Olá a todos! Aqui é a Ana e vamos ter mais uma videoaula sobre leitura. Dessa vez, nós vamos falar de leitura ativa. Alguns dias atrás, eu publiquei uma videoaula em que falava, afirmava que a leitura dinâmica, com a leitura rápida, ela não tinha bons resultados, ela sozinha não funcionava. Eu usei muitos dados da ciência cognitiva para fundamentar o que eu estava falando. Então, foi mais teórica. Hoje, vamos ter uma aula do ponto de vista mais prático.

No Trecho 4, constata-se a presença da abertura da aula com a identificação do sujeito e do conteúdo, além de ser uma continuidade de outra aula já ocorrida. Diante disso, essa estratégia proporciona situar o usuário/ leitor no assunto que será exposto, bem como, os créditos do apresentador(a). Embora, neste caso, só a reconheçamos pelo nome "Ana" e pela voz, não tendo o conhecimento do seu nível de profissionalização.

No fragmento a seguir, notam-se outras estratégias:

\section{Trecho 5:}

Agora, vamos falar de leitura ativa propriamente dita. Quais são as marcas de que você está fazendo uma leitura realmente ativa. Primeiro é o engajamento, você está engajado no texto, você realmente está dentro daquele texto, realmente tentando entender. A outra é que você está focado [...]. Com isso, você está fazendo uma leitura ativa, uma leitura produtiva que vai ter levar a um resultado muito mais rápido [...]. Então, o tempo todo você vai tentando diferenciar o que é essencial do que é acessório, pois isso te ajuda a pensar sobre o texto e quando a gente pensa em uma coisa tende a aprender melhor. 
O Trecho 5 apresenta o conceito de leitura ativa a partir de demonstração de exemplos de duas ações do leitor quando está diante do texto, sendo a primeira vinculada ao "engajamento, você está engajado no texto, você realmente está dentro daquele texto, realmente tentando entender. $A$ outra é que você está focado". Por foco e engajamento na leitura, depreende-se que o apresentador relaciona leitura ativa com interativa, isto é, a relação entre autor, texto e leitor (KLEIMAN, 2008).

Segundo Kleiman (2008, p.31), "Essa interação se refere ao inter-relacionamento, não hierarquizado dos diversos saberes do sujeito (desde o conhecimento gráfico até o conhecimento de mundo) utilizados pelo leitor". Portanto, nesta videoaula, o ensino da leitura ativa parte do princípio de que a sua realização depende de estratégias, uma delas, conforme a transcrição é a estratégia de sumarização: “Então, o tempo todo você vai tentando diferenciar o que é essencial do que é acessório, pois isso te ajuda a pensar sobre o texto e quando a gente pensa em uma coisa tende a aprender melhor".

A capacidade de síntese do leitor permite que tenha uma ideia global do texto, visto que a partir da leitura lexical serão mobilizados os conhecimentos de mundo para a produção semântica, cujas informações relevantes e de interesse 
daquele que lê passam a ser armazenadas na memória a longo prazo (KLEIMAN, 2008). Neste sentido, o ensino de leitura está entre os níveis de decodificação e de compreensão, o que requer um sujeito envolvido na obtenção de significados e na interpretação do texto verbal ou não verbal lido.

Em suma, a ocorrência de estratégias didáticas das Figuras 1, 2 e 3 revela que para este site a concepção de leitura está na transição entre o nível da decodificação e compreensão, isto é, entre o nível explícito e implícito não ocorrendo indícios para o nível metaplícito, em que se ensina ao leitor a ter posicionamento e senso crítico do que se lê. Quanto à organização composicional, a Figura 1 é um exemplo de aula gravada; a Figura 2 é um vídeo instrucional e a Figura 3 pode ser enquadrada no gênero videoaula.

Observa-se muito mais uma teorização e comandos de como se ler bem, do que sugestões de exemplos práticos que demonstrem a partir de textos a mobilização de estratégias de leitura. Esse recurso didático não se apresentou em nenhum dos vídeos deste site. Tal ocorrência comprova que a leitura é concebida do ponto de vista conceitual e não na inter-relação entre conhecimentos conceituais, procedimentais, atitudinais, os quais são adquiridos na interação do sujeito leitor com o texto, com a sua experiência escolar e de práticas culturais provenientes de seus grupos sociais (ARAÚJO; SILVEIRA, 2017). 


\section{CONSIDERAÇÕES FINAIS}

O ensino de Língua Portuguesa extrapolou os limites e os muros da escola, pois com o advento da internet, a informação se tornou mais acessível e rápida. Essa propagação veloz de conhecimentos científicos ocorreu através do recurso tecnológico vídeo. Esse reproduz imagens em movimento, acompanhado do recurso sonoro, para a exposição de conteúdos.

A análise dos vídeos do site Canal do Ensino, a partir da forma e do funcionamento, identificou 13 vídeos, sendo uma aula gravada que consiste na filmagem em tempo real de aulas presenciais; nove vídeos instrucionais, caracterizados pela sua natureza normativa e linear para a realização de procedimentos, neste caso, a da ação de ler. Tais vídeos são variações do gênero videoaula, embora, esses sejam assim popularizados. Além disso, apresentam uma concepção de ensino de leitura pautada na decodificação, o que pouco contribui para a construção de leitores críticos e letrados digitalmente.

Dentre estes, 03 são videoaulas que se afirmam como um gênero produzido para atender as demandas educacionais, em especial, do ensino a distância. Para tanto, servem como materiais didáticos, capazes de ilustrar, complementar, 
reforçar conteúdos já vistos. Quanto ao tratamento dado ao ensino de leitura, observa-se uma transição entre os níveis de decodificação para compreensão.

Portanto, a visualização estrutural e funcional para a caracterização desse gênero corroborou para responder à questão posta no início da pesquisa que indagava o que a concepção de videoaula diz sobre o tratamento dado ao ensino de leitura em site destinado a exames de larga escala.

Diante deste questionamento, nota-se que tais vídeos pouco favorecem um ensino de leitura metaplícito, pautado em habilidades de analisar, comparar, relacionar, e, sobretudo, de tomar um posicionamento crítico diante da ideia global do texto. Dessa forma, a ausência de abordagem pedagógica interativa nesse eixo demonstra que a figura docente ocupa espaço central no processo de ensino, mesmo, muitas vezes, tendo sido visto como desnecessário, em virtude dos aparatos tecnológicos.

Tal constatação evidencia que, embora as notícias sejam propagadas em tempo real, nem tudo que é veiculado é sinônimo deviabilidade edecredibilidade. Tal democratização, isto é, a liberdade que todo e qualquer usuário tem de postar e de fazer buscas de informações em sites, aplicativos, tem exigido que os internautas e os professores tenham olhares 
críticos sobre os materiais disponíveis em rede com vistas ao ensino e a aprendizagem de conteúdos. Para isso, é preciso que os docentes conheçam o funcionamento do material no ambiente virtual e quando deve ser utilizado em sala de aula.

\section{REFERÊNCIAS}

AMARAL, Adriana. NATAL, Geórgia. VIANA, Lucina (2008). "Netnografia como aporte metodológico da pesquisa em comunicação digital". Sessões do Imaginário, (20), Porto Alegre. , 34-40.

ARAÚJO, Denise Lino de (2014). Enunciado de atividades e tarefas escolares: modos de fazer. Olinda: Livro rápido, p.150.

; SILVEIRA, Maria de Fátima (2017). "A competência leitora nas provas de linguagens do enem". In: MARCUSCHI, Beth; LUNA, Tatiana Simões e. (Orgs.). Avaliação de língua portuguesa no novo enem. Jundiaí, SP: UniAnchieta. In http://www.portal.anchieta.br/anexos/livroavaliacao-lingua-portuguesa-novo-enem.pdf Acesso em 20.Jun.2018.

BARBOSA, Sandra Carla Pereira; SILVA, Williany Miranda (2017). "Estratégias de leitura empreendidas nos comentários postados nas redes sociais". Cadernos de Letras da UFF, 27(54), Jan./Jun., 213-236. Niterói.

BARRÉRE, Eduardo (2014). "Videoaulas: aspectos técnicos, pedagógicos, aplicações e bricolagem". III Congresso Brasileiro de Informática na Educação (CBIE). In https://www.br-ie.org/pub/index.php/pie/article/ view/3154/2668 Acesso em 25.Jun.2018.

CARDOSO, Carlos Adriano (2013). "O vídeo instrucional como recurso digital em educação a distância". Revista Trilha Digital, 1(1), 78-89. São Paulo.

COSCARELLI, Carla Viana; NOVAIS, Ana Elisa (2010). "Leitura: um processo cada vez mais complexo". Letras de Hoje, 45(3), Jul./Set., 35-42. Porto Alegre.

COSCARELLI, Carla Viana (2016). "Navegar e ler na rota do aprender". In: (Org.). Tecnologias para aprender. São Paulo: Parábola Editorial, p.61-80. 
DIONISIO, Angela Paiva; VASCONCELOS, Leila Janot (2013). "Multimodalidade, gênero textual e leitura". In: BUNZEN, Clecio; MENDONÇA, Márcia (Orgs.). Múltiplas linguagens para o ensino médio. São Paulo: Parábola Editorial, p.19-42.

VASCONCELOS, Leila Janot; DIONISIO, Angela Paiva (2013). "Multimodalidade, capacidade de aprendizagem e leitura". In: BUNZEN, Clecio; MENDONÇA, Márcia (Orgs.). Múltiplas linguagens para o ensino médio. São Paulo: Parábola Editorial, p.43-68.

DOMINGUEZ, Cláudia Rodriguez (2014). “O saber na tela: apropriação de gêneros e formatos televisivos em videoaulas para EaD”. 108f. (Dissertação de Mestrado) - Programa de Pós-graduação em Comunicação. São Caetano do Sul: USCS.FILATRO, Andrea (2008). Design Instrucional na Prática. São Paulo: Pearson Education do Brasil.

FONSECA, João José Saraiva da (2002). Metodologia da pesquisa científica. (Apostila). Fortaleza: UECE.

FRAGOSO, Suely; RECUERO, Raquel; AMARAL, Adriana (2013). Métodos de pesquisa para internet. Porto Alegre: Sulina.

KLEIMAN, Angela (2008). Leitura: ensino e pesquisa. Campinas: Pontes Editores.

MARCUSCHI, Luiz Antônio (2010). "Gêneros textuais emergentes no contexto da tecnologia digital". In: MARCUSCHI, Luiz Antônio; XAVIER, Antônio Carlos (Orgs.). Hipertexto e gêneros digitais: novas formas de construção do sentido. Rio de Janeiro: Lucerna. p.15-81.

MAYER, Richard (2001). Multimedia Learning. Cambridge: Cambridge University Press.

MIRANDA, Florencia (2015). "Considerações sobre o ensino de gêneros textuais: pesquisa e intervenção". In: MIRANDA, Florencia; COUTINHO, Maria Antónia; LEURQUIN, Eulália. Formação Docente: textos, teorias e práticas. Campinas, Mercado de Letras.

OLIVEIRA, Alexandre. STADLER, Pâmella de Carvalho (2014). Videoaulas: uma forma de contextualizar a teoria na prática. In http://www.abed.org. br/hotsite/20-ciaed/pt/anais/pdf/352.pdf Acesso em: 15.Dez.2016. 
PEREIRA, Daniervelin Renata Marques (2014). "O estilo dos gêneros digitais". Estudos semióticos, 10(2), 53-65.

RIBEIRO, Ana Elisa (2016). "Leitura, escrita e tecnologia: questões, relações e provocações". In: COSCARELLI, Carla Viana (Org.). Tecnologias para aprender. São Paulo: Parábola Editorial, p.31-42.

VIEIRA, Josenia; SILVESTRA, Carminda (2015). Introdução d̀ Multimodalidade: Contribuições da Gramática Sistêmico-Funcional, Análise de Discurso Crítica, Semiótica Social. Brasília, DF: J. Antunes Vieira. VELOSO, Francisco O. Dourado (2014). "Pesquisa em multimodalidade: por uma abordagem sociossemiótica". In: GONÇALVES, Adair Vieira; SILVA, Wagner Rodrigues; GÓIS, Marcos Lúcio de Sousa (Orgs.). Visibilizar a linguística aplicada: abordagens teóricas e metodológicas. Campinas, SP: Pontes. p.155-190.

ZABALA, Antoni (2009). A prática educativa: como ensinar. Ernani da Fonseca Rosa (Trad.). Porto Alegre: Artmed.

ZACHARIAS, Valéria Ribeiro de Castro (2016). "Letramento digital: desafios e possibilidades para o ensino". In: COSCARELLI, Carla Viana (Org.). Tecnologias para aprender. São Paulo: Parábola Editorial, p.15-30.

Katianny Késia Mendes Negromonte Targino é Graduada em Letras com ênfase em Língua Portuguesa e Mestre em Linguagem e Ensino pela UFCG. O presente artigo, nomeado de "Saberes sobre leitura em videoaulas de midias digitais" está vinculado ao projeto de pesquisa, intitulado Novas configurações de ensino de leitura e escrita em atividades de linguagem(ns), cuja autora faz parte.

E-mail: katiannykessiakmn@gmail.com

Williany Miranda da Silva é professora Doutora da UFCG, desenvolve trabalhos, com ênfase em Leitura e Produção de Textos, destacando-se os seguintes temas: materiais didáticos, ambientes digitais, concepções de ensino, formação docente, livro didático, escrita e oralidade. Com estágio de pós-doutoramento concluído pela Universidade Federal de Minas Gerais (2013), atualmente desenvolve projetos de pesquisa; envolvendo tecnologias, linguagens, gêneros textuais 
orais e escritos e atuação docente, com orientações tanto na pós-graduação quanto na graduação, em programas PIBIC e PIBID - Letras, em que atuou como coordenadora do subprojeto PIBID -LETRAS, de 2016 a 2018. Membro do grupo de pesquisa Teorias da linguagem e ensino, na linha de pesquisa Lingua(gem) em contexto de ensino de português.

E-mail: williany.miranda@gmail.com 